\title{
Research Paper: The Effect of Educating Confronting Accidents and Disasters on the Improvement of Nurses' Professional Competence in Response to the Crisis
}

\author{
Maryam Latif $^{1}$ (D), Mohammad Abbasi ${ }^{1 *}$ id, Somayeh Momenian ${ }^{1}$ \\ 1. Department of Nursing, Faculty of Nursing and Midwifery, Qom University of Medical Sciences, Qom, Iran.
}

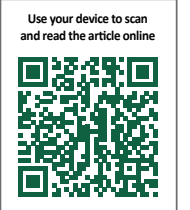

CitrationLatif M, Abbasi M, Momenian S. The Effect of Educating Confronting Accidents and Disasters on the Improvement of Nurses' Professional Competence in Response to the Crisis. Health in Emergencies and Disasters Quarterly. 2019; 4(3):147-156. http://dx.doi.org/10.32598/hdq.4.3.147

dol : http://dx.doi.org/10.32598/hdq.4.3.147

Article info:

Received: 25 Aug 2018

Accepted: 02 Feb 2019

Available Online: 01 Apr 2019

\section{Keywords:}

Education, Professional competence, Nurse

\begin{abstract}
Background: To achieve the highest possible level of health for individuals and societies involved in the crisis, a high level of individual and professional competency is needed in nurses for their active participation in the crisis. The acquisition of professional qualifications by nurses to provide care in the crisis is very important. The present study aimed to determine the effect of disaster and accident response training on the enhancement of professional competence of nurses in response to the crisis.

Materials and Methods: This research was a quasi-experimental study with pre-test, post-test design. The statistical population consisted of all nurses working in Shahid Chamran Hospital in Saveh City, Iran, in 2017. In total, 80 nurses were selected through the convenience sampling method and were randomly divided into the intervention and control groups. The intervention group received training through lectures and workshops for 16 hours in 4 days. The samples completed a professional nursing competency assessment questionnaire before and one month after the intervention. The obtained data were analyzed by the Chi-squared test, Fisher's exact-test, Independent samples t-test, and Paired samples t-test in SPSS.
\end{abstract}

Results: The findings revealed no significant difference between the two groups concerning demographic variables. After the intervention, the average improvement of professional competence of nurses in their ability to manage the accident scene increased from 63.3 to 74.07 , teamwork skill from 56.7 to 74 , individual specific abilities from 61.4 to 70 , ethical performance from 67.8 to 76.9 , and professional skills from 54 to 60 . The Mean \pm SD pretest score of professional competency of nurses in the intervention and control groups were $163.5 \pm 28.6$ and $155.73 \pm 34$, respectively. After the intervention, these scores increased to $185.13 \pm 28.8$ and $158.48 \pm 33.3$ in the intervention and the control groups, respectively. The difference was statistically significant in the intervention group $(\mathrm{P}<0.001)$.

Conclusion: The findings of this study indicated that the competence of nurses to provide care in crises was not at a desirable level. Thus, assessing the competence of nurses and identifying the gaps in their knowledge and skills before attending crises is essential. Also, the incident and disaster education can dramatically increase nurses' professional competence in responding to the crisis. Therefore, we suggest the method used in this study as a feasible, simple, low cost and effective method in this regard.

\section{* Corresponding Author:}

Mohammad Abbasi, PhD

Address: Department of Nursing, Faculty of Nursing and Midwifery, Qom University of Medical Sciences, Qom, Iran.

E-mail:Mohamad_abbasi55@yahoo.com 


\section{Introduction}

he present world experiences natural or human-made disasters every day. These

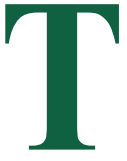
disasters usually turn into a crisis in societies [1]. Crisis refers to a situation where people lose their supportive means of life, which is the result of natural or humanmade disasters [2]. The World Health Organization (WHO) recognizes incidents and disasters as a condition where local equipment and tools required to protect people's lives are lost due to natural or humanmade disasters.

The world has gone through incidents, emergencies, and crises in recent years that their deadly human effects have been undeniable. According to the latest report in the past decade, the incidents have become more complex, and the impacts of natural disasters worldwide accounted for the death of 700000 people, injuries of 4.1 million, homelessness of 23 million, and 1.3 trillion dollars' worth of economic damage [3]. According to available statistics, 346 natural disasters occurred worldwide in 2015. These events affected the lives of nearly 100 million people, killing 22773 people. Of these disasters, 152 events have occurred in the ancient Asia continent [4].

When disasters occur, nurses are the first responders to critical conditions in the healthcare team [5]. As the largest professional group in the healthcare team, nurses have a crucial role in managing disasters [4]. Correct, timely, and appropriate nursing practices are the main factors in survival, mortality reduction, and well-being of individuals in the aftermath of accidents and disasters [6]. These factors are associated with the level of nurses' professional preparedness and competence [7].

The professional competence of nurses defined by the International Association of Nurses includes critical thinking skill, technical skills, and the ability to communicate effectively [8]. In general, competence comprises the combination and application of knowledge, expertise, and personal abilities to carry out professional roles safely and ethically. Nurses should know the basic knowledge about health promotion, risk reduction, and disease prevention in crisis [9]. They must also have a proper understanding of the structure and command of the scene, triage methods and protocols, personal protection equipment, scene evaluation, and comprehensive emergency management [10].
The inadequacy of nurses' skills and competency to play an active role and provide the necessary care to the victims of the crisis can result in exacerbating the problem and irreversible complications to victims and society [7]. Therefore, nurses must gain professional and technical skills such as using the emergency equipment, triage, and providing biopsychological care to the injured and survivors of accidents and disasters before facing crises [2].

Nurses also need to know scientific information about critical situations and events to take effective measures in crisis because the combination of knowledge and care skills provide the necessary competence to manage the crisis and to play an effective role in critical situations [11]. The lack of competency can result in the inappropriate performance of nurses in caring victims of disasters. Therefore, assessing the competence of nurses and identifying the gaps in their knowledge and skills before attending critical situations is essential.

This assessment not only helps managers and nurses to know better the nurses' level of competence but also can reduce the risks involved in the ineffective response to the disasters. The main goal in the crisis is to achieve the best possible level of health for the involved individuals and society in the crisis. To achieve this goal, nurses need high levels of individual and professional competencies to have an active presence in the crisis [12].

One of the methods to promote nursing competency suggested in various studies is education, which is used to increase the nurses' preparedness in providing emergency services. Based on research, most nurses in Iran have not passed any training to manage accidents and disasters and usually gained some experience because of participating in previous accidents and disasters. And if they received some education, the training would not be adequate.

Such a lack of planning and organization to manage incidents, preparedness, coordination, and staff training for crisis management can result in irreparable damages to the health system of the country and people [13]. The World Health Organization considers the preparedness of nurses and trained personnel an effective factor in reducing the number of casualties caused by disasters [14]

Khankeh has also introduced trained people as one of the facilitating factors in providing healthcare services [15]. Bartly also mentioned the training of healthcare staff as a major component of disaster preparedness [16]. Training is vital in raising the appropriate and prompt 
response of nurses to the crisis; however, little information is available on the skills or competencies required by the nurses for the effective presence of the crisis team in these situations.

The required capabilities of nurses to effectively perform tasks and how they play their role in a crisis have not been well explained, too [17]. The education has an essential role in promoting the professional competence and empowerment of nurses and consequently its effect on saving the lives of patients, reducing the injuries due to crises, and assessing the preparedness and competence of nurses before facing a crisis.

Furthermore, education is also necessary for the selection of qualified personnel to attend the crisis team and the preparation of nurses for critical situations. Thus, the present study was conducted to determine the effectiveness of the program of coping with accidents and disasters on the promotion of the professional competence of nurses. This study is a step toward preventing and reducing casualties in disasters.

\section{Materials and Methods}

This research was a quasi-experimental study with a pretest-post-test design and a control group. The study population comprised all nurses working in Shahid Chamran Hospital in Saveh City, Iran, from March 2018 to September 2018. The minimum sample size was calculated as 40 samples for each group based on the study by Ali Akbari et al. as well as the sample size formula :

$$
n=\frac{\left(z 1-\frac{a}{2} z 1-\beta\right) 2\left(S 1^{2}+S 2^{2}\right)}{(\mu 1-\mu 2) 2}
$$

The probability of the type I error was considered 0.05 , test power as 0.90 , and we considered the minimum value of the significant difference. The samples were selected based on inclusion criteria, including willingness to participate in the study and providing informed consent, having at least a bachelor's degree in nursing, non-participation in incident management education programs in the last three months, full-time employment in Shahid Chamran Hospital in Saveh City, and having at least one year work background.

The exclusion criteria were leaving the study or the absence of more than one session from the training sessions. We used a convenience sampling method, and after selecting 80 people, they were allocated into two groups of 40 intervention and control groups by using block randomization method. The study data were collected using two questionnaires.

The first one investigated the subjects' demographic characteristics, including age, gender, marital status, educational level, job status, work experience, ward, and work shift. The second questionnaire was used for assessing the competence of nurses. The questionnaire consisted of 5 subscales for providing care in disasters and accidents. These subscales were "scene management ability in accidents and disasters", "ethical and legal performance in accidents and disasters", "teamwork skills in accidents and disaster", "individual capabilities of nurses", and "professional skills of nurses".

The questionnaire was designed by Ali Akbari and colleagues in 2013. In each of the 5 domains, the highest score of $70 \%$ or above indicates desirable (very good/ good), the scores of $50-70 \%$ indicate average and scores of below 50\% suggests the unacceptable and weak performance of the respondent. This questionnaire is a valid

Table 1. The content of training sessions for confronting accidents and disasters

\begin{tabular}{|c|c|}
\hline Session & Educational Content \\
\hline 1 & $\begin{array}{l}\text { Introducing, explaining the method of work, goals, and rules of the group, titles on the importance of nurses' } \\
\text { preparedness in confronting disasters and accidents, familiarity with the incident command system, hospital crisis } \\
\text { team }\end{array}$ \\
\hline 2 & $\begin{array}{l}\text { Teamwork, motivating teamwork and its importance, how to communicate effectively with other team mem- } \\
\text { bers, patients, and their companions, the methods of prevention and elimination of conflict in the group, how to } \\
\text { eliminate heterogeneity in treatment groups and adopt appropriate solutions and familiarity with the benefits of } \\
\text { teamwork, familiarity with group decision-making methods, and the implementation of workshops to address the } \\
\text { potential problems of participants in teamwork }\end{array}$ \\
\hline 3 & $\begin{array}{l}\text { Educating special skills of nurses in emergency situations such as learning how to care for trauma patients, holding } \\
\text { a practical workshop on suturing and splints, familiarity with the principles of triage at the accident scene and in } \\
\text { the hospital, a practical workshop for cardiopulmonary resuscitation, and familiarity with the correct methods of } \\
\text { transportation of patients, immobilization, and the principles of providing care for burn patients }\end{array}$ \\
\hline 4 & $\begin{array}{l}\text { The necessary characteristics of nurses in crisis, carrying out round-the-table and practical maneuvers on how to } \\
\text { evaluate initial injuries, teamwork management and the proper care of injured patients }\end{array}$ \\
\hline
\end{tabular}


and reliable tool. The content validity, face validity, and construct validity of the tool were investigated and approved by Ali Akbari and his colleagues.

The internal consistency assessment by Cronbach $\alpha$ coefficient was higher than 0.88 for all subscales of the questionnaire and 0.96 for the whole scale. The test-retest method was also used to assess the reliability of the questionnaire. For this purpose, the questionnaire was completed by 30 persons eligible to enter the study, two times in a two-week interval. The correlation coefficient between the two assessments in all subscales of the questionnaire was higher than 0.9 [18].

After conducting the pretest, the training classes for confronting accidents and disasters were carried out by delivering lectures and holding daily practical workshops for 16 hours in 4 days (Table 1). Each session was held by 40 people and run by two of the researchers. There was no intervention for the control group. One month after the intervention, nurses from both groups conducted a post-test, and the data were collected and analyzed by the Chi-squared test, Fisher's exact-test, Independent samples t-test, and Paired samples t-test in SPSS. To observe the research ethics, the study was approved by the Ethics Committee of Qom University of Medical Sciences (Code: IR.MUQ.REC.1397.026).

Moreover, the researcher introduced himself and explained the objectives of the study for the samples, and reminded that their participation was voluntarily and had no effect on their evaluation process. We also mentioned that their information would remain confidential. After completing the study, all the contents of the training sessions were also taught to the control group.

\section{Results}

A total of 80 people participated in this study. The Chisquared test results indicated no significant difference between the two groups in terms of the distribution of occupation position $(\mathrm{P}=0.52)$. Additionally, the Fisher's exact-test results demonstrated that gender distribution $(\mathrm{P}=0.45)$, educational level $(\mathrm{P}=0.99)$, employment status $(\mathrm{P}=0.23)$, and marital status $(\mathrm{P}=0.46)$ were not significantly different between the two groups. Based on the Independent Samples t-test results, the mean scores of age $(\mathrm{P}=0.42)$ and work experience $(\mathrm{P}=0.12)$ were not significantly different between the two groups (Table 2).

Based on the study purpose, the mean score of professional competence in crisis response was evaluated in the two groups of intervention and control (Table 3).
Considering the normal distribution of data before and after the intervention in both groups, the Independent samples t-test, and Paired samples ttest were used. According to the Independent samples t-test results, the Mean \pm SD pretest score of nurses' professional competency in the intervention and control groups were $163.5 \pm 28.6$ and $155.34 \pm 73$, respectively. Their post-test Mean \pm SD scores were $185.13 \pm 28.8$ and $158.33 \pm 48.3$ in the intervention and control groups, respectively. The difference was significant in the intervention group $(\mathrm{P}<0.001)$ (Table 3).

Furthermore, in the control group, the mean pretest and post-test scores were not significantly different from each other $(\mathrm{P}=0.09)$; while in the intervention group, this difference was significant $(\mathrm{P} \leq 0.001)$. In this study, the professional competency subscale mean scores of nurses were evaluated in the intervention and control groups.

According to the results, there was no significant difference between the pretest and post-test scores of the control group in the subscale of scene management ability $(\mathrm{P}=0.15)$. However, scene management ability scores in the intervention group was significantly different between the pre-test and post-test phases $(\mathrm{P}<0.001)$. The post-test score of scene management ability increased 2.72 units in the intervention group, compared to the control group (Figure 1).

The second subscale of teamwork skill in crisis was evaluated by the Paired samples t-test in the intervention and control groups before and after the intervention. Based on the results, there was a significant difference between the pre-test and post-test scores of this subscale in the intervention group $(\mathrm{P}>0.001)$. There was a significant difference in the post-test scores between the two groups, too $(\mathrm{P}=0.01)$. This finding suggests that teamwork skill in crisis in the post-intervention phase increased up to 1.81 unit in the intervention group, compared to that in the control group.

The third subscale was determining and comparing the individual capabilities between the two groups before and after the intervention. Based on the results, there was a significant difference in the individual capabilities between the pre-test and post-test scores in the intervention group $(\mathrm{P}<0.001)$. The Independent samples t-test assessed the difference between the pre-test and post-test scores of the intervention and control groups. These results suggested no significant difference in the individual capabilities between the experimental and control groups before conducting the intervention $(\mathrm{P}=0.32)$. 
Table 2. The demographic characteristics of the study participants

\begin{tabular}{|c|c|c|c|c|}
\hline \multirow{2}{*}{\multicolumn{2}{|c|}{ Group }} & \multicolumn{2}{|c|}{ No. (\%) } & \multirow{2}{*}{$\mathbf{P}$} \\
\hline & & Intervention & Control & \\
\hline \multirow{3}{*}{ Gender* } & Male & $12(30)$ & $9(5.22)$ & \multirow{3}{*}{0.45} \\
\hline & & & & \\
\hline & Female & $28(70)$ & $31(5.77)$ & \\
\hline \multirow{3}{*}{ Marital status* } & Single & $5(12.5)$ & $3(5.7)$ & \multirow{3}{*}{0.46} \\
\hline & & & & \\
\hline & Married & $35(87.5)$ & $37(5.92)$ & \\
\hline \multirow{3}{*}{ Job position** } & Nurse & $34(85)$ & $37(5.92)$ & \multirow{3}{*}{0.52} \\
\hline & Nursing head & $4(10)$ & $2(5)$ & \\
\hline & Supervisor & $2(5)$ & $1(5.2)$ & \\
\hline \multirow{3}{*}{ Educational level* } & BA & $39(97.5)$ & $39(5.97)$ & \multirow{3}{*}{0.99} \\
\hline & & & & \\
\hline & MA & $1(2.5)$ & $1(5.2)$ & \\
\hline \multirow{3}{*}{ Work contract type* } & Official & $25(62.5)$ & $30(75)$ & \multirow{3}{*}{0.23} \\
\hline & & & & \\
\hline & Non-official & $15(37.5)$ & $10(25)$ & \\
\hline
\end{tabular}

\begin{tabular}{|c|c|c|c|}
\hline \multirow{2}{*}{ Group (y) } & \multicolumn{2}{|c|}{ Mean $\pm S D$} & \multirow{2}{*}{$\mathbf{P}$} \\
\hline & Intervention & Control & \\
\hline $\mathrm{Age}^{* * *}$ & $31.35 \pm 5.4$ & $25.36 \pm 9.4$ & 0.42 \\
\hline Work experience ${ }^{* * *}$ & $9.97 \pm 5.5$ & $11.67 \pm 8.5$ & 0.21 \\
\hline
\end{tabular}

*The Fisher's exact-test; ** The Chi-squared test; ${ }^{* * *}$ The Independent samples t-test. Emergencies and [D]isasters [0luarterly

However, the difference in the mean post-test score of special capabilities in the intervention and control groups was significant $(\mathrm{P}=0.001)$. There was a significant difference between the two groups in terms of individual capabilities after the intervention $(\mathrm{P}=0.01)$. That is, the post-test score of specific individual capabilities in the intervention group 2.08 units increased compared with that in the control group.
The fourth subscale was the pre-test, and post-test mean score of the ethical and legal performance in the intervention and control groups. This difference between the pre-test and post-test scores of the intervention and control groups was investigated by the Paired samples t-test. The obtained results indicated a significant difference between the mean score of ethical and legal practice before and after the intervention in the intervention group $(\mathrm{P}<0.001)$

Table 3. Comparison of the mean professional competence between two groups.

\begin{tabular}{|c|c|c|c|}
\hline \multirow{2}{*}{ Variable } & \multicolumn{2}{|c|}{ Mean $\pm S D$} & \multirow{2}{*}{$\mathbf{P}$} \\
\hline & Intervention & Control & \\
\hline Competency level before the crisis management intervention & $163.5 \pm 28.6$ & $155.73 \pm 34.00$ & 0.27 \\
\hline Competency level after the crisis management intervention & $185.13 \pm 28.8$ & $158.48 \pm 33.3$ & $\geq 0.001$ \\
\hline $\mathrm{P}$ & $\geq 0.001$ & 0.09 & \\
\hline
\end{tabular}




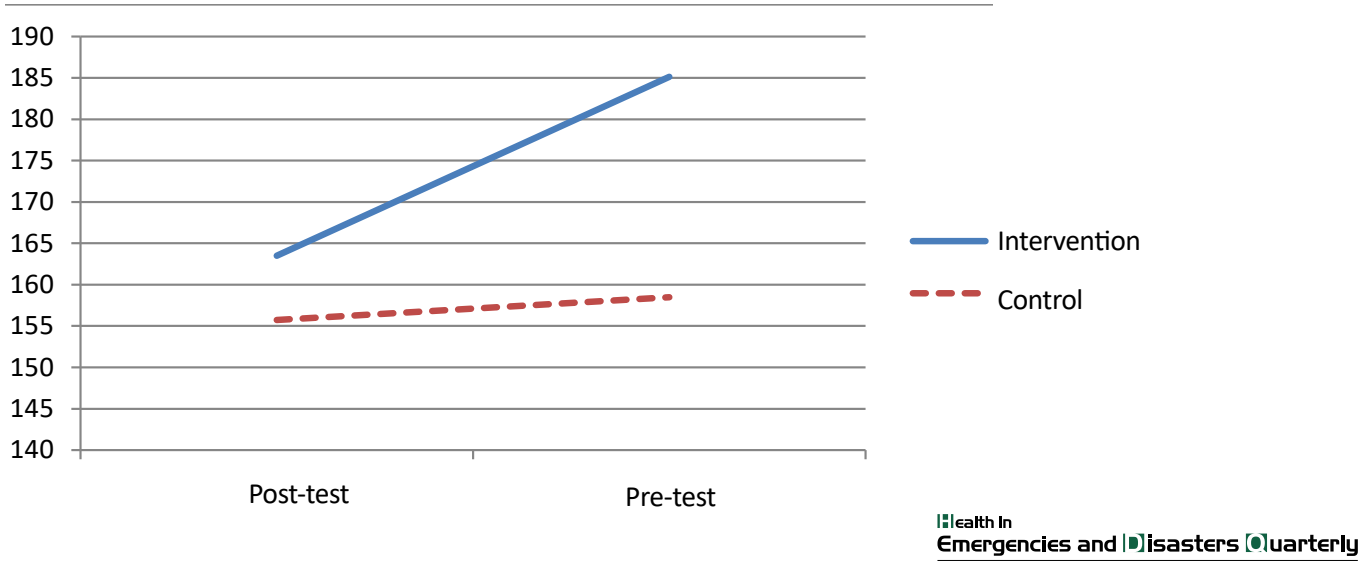

Figure 1. The mean pretest-posttest trend of the professional competence of nurses in response to the crisis in the two groups

The pre-test, post-test difference between the intervention and control groups was assessed using the Independent samples t-test. The results revealed no significant difference between the two groups in terms of ethical and legal practice between the intervention and the control groups at pre-test phase $(\mathrm{P}=0.32)$. However, the difference between the legal and ethical performance of the intervention and control groups was significant after the intervention $(\mathrm{P}=0.04)$. That means, the level of legal and ethical performance increased by 1.6 units in the experimental group at post-test compared to that in the control group.

The fifth subscale was the professional skills in the intervention and control groups before and after the intervention. The Paired samples t-test evaluated the intragroup difference between the intervention and control before and after the intervention. In the intervention group, there was a significant difference between before and after the intervention with regard to the professional skills subscale $(\mathrm{P}=0.001)$.

The difference in the post-test mean score of professional skills in the intervention and control groups was significant $(\mathrm{P}=0.02)$. There was a significant difference in the post-test scores between the two groups in terms of professional skills $(\mathrm{P}=0.04)$. In other words, the level of professional skills after the intervention was 2.06 units higher in the intervention group compared with that in the control group.

\section{Discussion}

This study examined the level of working nurses' competencies for providing care in the crisis response phase, as well as the impact of training on promoting these competencies. Based on the obtained results, the average professional competence of nurses in response to the crisis was not desirable. However, after conducting the intervention, the intervention group's competency increased, but no significant difference was seen in the control group in this regard.

Therefore, training to cope with disasters can help improve nurses' professional competence in response to the crisis. The results of some previous studies are in line with the findings of this study. Ali Akbari et al. (2017) conducted a study on the assessment of the competency of emergency nurses to provide care in critical situations using an Objective Structured Clinical Examination (OSCE). In this descriptive study, 25 nurses working in the emergency departments of Shahrekord Educational Hospitals were evaluated in terms of assessing nursing competencies for providing nursing care in crisis consisting of 8 stations [10].

The findings demonstrated that the mean scores of the research samples performance in each of the 8 skills (airway management, life support, IV therapy, IV line insertion, chest tube insertion, triage, suturing, nasogastric tube insertion, and urinary catheterization) were lower than the average. The obtained results indicated that the competency of the studied nurses to provide care in critical situations was not at the optimum level, and it was lower than the average for all skills.

Therefore, all nurses were required to obtain significant, clinical, and specialized skills and receive professional training in this regard [10]. Additionally, Aal Khalileh et al. in a cross-sectional study examined the perception of Jordanian nurses about their readiness for crisis management. They investigated 474 nurses using the Arabic version of the crisis pre-paredness assessment questionnaire. The results revealed that $65 \%$ reported their pre-paredness as weak, 18\% moderate, $12 \%$ good, and 5\% very good. 
Their results indicated that nurses with inadequate experience in this area and crisis management, maneuver, or similar situations have not been able to function in critical situations effectively [19]. Ali Akbari et al. assessed the competence of emergency nurses in critical situations. Their results revealed that in the managerial competence area, the participants' average competence score was estimated as $88.8 \%$, indicating the desirable evaluation of nurses from their competence in this area [10].

In terms of ethical and legal competence, the participants achieved a score of $82.72 \%$, which indicated that nurses had a good assessment of their competence in this area. In terms of individual special capabilities, the overall competency was estimated at $72.73 \%$, which indicated nurses' desirable evaluation of their abilities in this area. In the area of professional and technical competencies, the participants assessed their total competence score in the field of professional and technical competence as $67.75 \%$, which indicated that nurses assessed their qualifications as average.

An accurate review of the technical and professional competencies associated with nursing in a crisis shows that nurses are qualified in their routine daily work in hospitals and non-crisis conditions; however, they lack competencies on issues such as the skill of working with pre-hospital emergency equipment, triage skills, and providing biopsychological care during a crisis. Overall, in this study, nurses rated their capability in ethical and legal contexts better than other aspects; while, in the technical and professional competencies, they had the least qualifications [18].

The results of this study also indicate that the mean score of nursing competency is not the same in different areas. Furthermore, after the training sessions, workshops, and holding maneuvers, the average score of professional competence was different in various areas. After the implementation of educational interventions, the ability to manage the scene increased from 63.3 to 74.7 , teamwork skill from 56.5 to 74 , individual abilities from 61.4 to 70 , ethical performance from 67.8 to 76.9 , and professional skills from 54 to 60 . The highest score of nurses belonged to the field of ethical and legal performance and the lowest score to the field of professional skills, which is consistent with the results of the studies by Ali Akbari.

A study by Mohebbi aimed at determining and comparing the professional competencies of nurses working in the emergency department of educational hospitals and pre-hospital emergency hospitals in Tehran in response to accidents and disasters. The results of the present study indicate that professional competence assessment for nurses working in all sectors is essential, and this assessment should become a continuous process to be used as a tool for ranking and encouraging nurses.

Also, to be ensured of the nurses' performance in clinical settings and evidence-based management, we should focus on the systematic assessment of the professional competence of care providers. Professional competency assessment models should be integrated with the quality assurance systems and human resource management [20].

Bahrami et al. conducted a study to assess the competence of teamwork in response to the crisis from the viewpoint of emergency nurses. Their results show that nurses should be completely familiar with their own duties and others' responsibilities in the crisis management team, recognize the management hierarchy in response to the crisis, and be able to maintain the unity of command for effective teamwork in crisis. Therefore, educating in-service nurses should be considered by hospitals' authorities to prepare them for crisis response [21]. Rahmati et al. conducted a study to determine the effect of crisis management training on high-casualties traffic accidents with simulated training method on the knowledge and attitude of nursing staff. The findings of this study demonstrate that training by simulation training and workshop can improve the knowledge and attitudes toward crisis management better than holding workshop alone [22].

Inkaew and Chompunud (2017) conducted a study to investigate the effect of the interactive educational method on the competence of nursing students on disasters. In this interventional study, 92 third-year students were randomly assigned to the intervention and control groups. Training on disaster management, nursing disaster, first aid, triage, and nursing care was provided to the intervention group, and the competence of the two groups was assessed in the areas of preparedness, prevention, harm reduction, and response. The results revealed that the changes in the intervention group were significant [23].

Motaqian Nejad et al. studied 83 nurses and stated that the use of hospital incident management training was effective in improving the preparedness of nursing staff [24]. Ghanbari et al. conducted a study to determine the effect of disaster preparedness planning on nursing staff readiness for responding to potential natural disasters. It was a quasi-experimental single-group study with a pretest, post-test design. Their results indicate that the nursing staff's knowledge and attitudes in response to probable natural disasters improve after receiving disaster 
and accident training. Eventually, the researchers argued that training for disaster preparedness programs should be part of the continuing education of nurses to establish and maintain the readiness of the nursing staff [6].

A quasi-experimental study by Amerion et al. on the areas of preparedness of the staff before and after the intervention showed the heterogeneous promotion of these areas during trauma maneuver intervention; one of the most important reasons for their weakness is scenario planning. Therefore, the issue of health and medical personnel's readiness should be addressed by the policymakers and senior managers of the health system and should not be limited to a maneuver [25].

Shafie et al. conducted a thesis entitled "The Effect of Training of the Principles of Increasing Extra-Capacity in Nurses on the Level of Preparedness in Response to Probable Accidents" at the University of Welfare and Rehabilitation Sciences of Tehran. The findings of that study reveal that the training program can increase the level of preparedness in response to possible hospital accidents in some aspects [26].

Karimian et al. concluded that a national disaster response program training had a positive impact on accidents and disasters response preparedness of hospitals [27]. Delshad et al. examined the effect of the rapid warning system on the preparedness of Motahari Hospital in accidents and disasters. They found that educational intervention is very important in increasing hospital readiness in accidents and disasters [28].

\section{Conclusion}

Our study results reveal that incident and disaster education increases the professional competence of nurses in response to the crisis and each of its dimensions (scene management ability, crisis teamwork skills, individual special capabilities, ethical and legal performance, and professional skills). This finding indicates that this educational and practical plan as an educational and managerial intervention (especially in terms of nursing crisis management, as an essential and practical part of the hospital management team), can affect the professional competence of nurses in response to the crisis. In other words, it provides appropriate and high standards in terms of professional competence in response to the crisis for all nurses and especially nurses of the crisis committees.

Many nurses overlook paying attention to the methods of managing accidents and disasters, neither during uni- versity education nor during the working period. Therefore, it is necessary for nurses to receive training for crisis management in addition to their specialized nursing skills.

\section{Ethical Considerations}

\section{Compliance with ethical guidelines}

The present was getting informed consent before the study begins confidentiality of evaluation results training the control group after the end of the study.

\section{Funding}

The present study was part of a Master's thesis of the first author, Department of Nursing, Faculty of Nursing and Midwifery, Qom University of Medical Sciences (Code: IR.MUQ.REC 1397.026) and conducted at Shahid Chamran Hospital in Saveh City, Iran.

\section{Authors' contributions}

Methodology: Maryam Latif, Mohammad Abbasi, Somayeh Momenian; Investigation: Maryam Latif; Writing-original draft: Maryam Latif; Writing-review \& editing:Maryam Latif, Mohammad Abbasi, Somayeh Momenian; Funding acquisition: Maryam Latif, Mohammad Abbasi; Resources: Maryam Latif, Mohammad Abbasi, Somayeh Momenian; Supervision: Mohammad Abbasi.

\section{Conflict of interest}

The authors declared no conflict of interest.

\section{Acknowledgments}

we are very grateful to the graduate students of the university and the cooperation of the chair and management of the nursing staff of Shahid Chamran Hospital and all the staff members who collaborated in this research.

\section{References}

[1] Geravandi S, Soltani F, Mohammadi MJ, Salmanzadeh S, Shirali S, Shahriari A et al. [The effects of increasing the capacity of admission in emergency ward in increasing the rate of patient acceptance at the time of crisis (Persian)]. Armaghane Danesh. 2016; 20(12):1057-69.

[2] Aliakbari F, Bahrami M, Aein F, Khankeh H. Iranian nurses' experience of essential technical competences in disaster response: A qualitative content analysis study. Iranian Jour- 
nal of Nursing and Midwifery Research. 2014; 19(6):585-92. [PMID] [PMCID]

[3] Khankeh HR. [National hospital risk management guide accreditation indicators (Persian)]. Tehran: Ministry of Health and Medical Education; 2017.

[4] Noguchi N, Inoue S, Shimanoe C, Shibayama K, Shinchi K. Factors associated with nursing activities in humanitarian aid and disaster relief. Public Library of Science. 2016; 11(3):e0151170. [DOI:10.1371/journal.pone.0151170] [PMID] [PMCID]

[5] Chan SSS, Chan W, Cheng Y, Fung OWM, Lai TKH, Leung AWK et al. Development and evaluation of an undergraduate training course for developing International Council of Nurses disaster nursing competencies in China. Journal of Nursing Scholarship. 2010; 42(4):405-13. [DOI:10.1111/j.15475069.2010.01363.x] [PMID]

[6] Ghanbari V, Maddah SS, Khankeh HR, Karimloo M. [The effect of a disaster nursing education program on nurses' preparedness for responding to probable natural disasters (Persian)]. Iran Journal of Nursing. 2011; 24(73):72-80.

[7] Bahrami M, Aliakbari F, Aein F. Investigation of competencies of nurses in disaster response by utilizing objective structured clinical examination. Iranian Journal of Nursing and Midwifery Research. 2014; 19(7 Suppl. 1):S1-6. [PMID] PMCID]

[8] Turale S, Grace J, Prasopkittikun T, Tilokskulchai F, Vipuro $\mathrm{N}$, Thananowan N, et al. Nurses: Are we ready for a disaster? Journal of Nursing Science. 2010; 28(1):8-11.

[9] Yang Y, Xiao LD, Cheng H, Zhu J, Arbon P. Chinese nurses' experience in the Wenchuan earthquake relief. International Nursing Review. 2010; 57(2):217-23. [DOI:10.1111 /j.1466-7657.2009.00795] [PMID]

[10] Aliakbari F, Aien F, Bahrami M. [Assessment competencies among emergency nurses for responding in disaster situation with Objective Structured Clinical Examination (Persian)]. Journal of Health Promotion Management. 2014; 3(3):47-57.

[11] Kavanagh JM, Szweda C. A crisis in competency: The strategic and ethical imperative to assessing new graduate nurses' clinical reasoning. Nursing Education Perspectives. 2017; 38(2):57-62. [DOI:10.1097/01.NEP.0000000000000112] [PMID]

[12] Xu Y, Zeng X. Necessity for disaster-related nursing competency training of emergency nurses in China. International Journal of Nursing Sciences. 2016; 3(2):198-201. [DOI:10.1016/j.ijnss.2016.04.009]

[13] Mohammadi S, Aminisaman J, Karimpour H, Kaviannezhad R, Ezzati E. [Assessing of preparedness for disasters and crisis in centers of trauma and accidents of Kermanshah university of medical sciences in 2016 (Persian)]. Journal of Clinical Nursing and Midwifery. 2017; 6(2):69-80.

[14] WHO. Risk reduction and emergency preparedness: WHO six-year strategy for the health sector and community capacity development. Geneva: World Health Organization; 2007.

[15] Khankeh H, Mohhamadi R, Ahmadi F. Facilitator and barrier factor for health services in natural disaster. Journal of Rehabilitation. 2006; 6(1):23-30.

[16] Hsu EB, Thomas TL, Bass EB, Whyne D, Kelen GD, Green GB. Healthcare worker competencies for disaster training.
BMC Medical Education. 2006; 6(1):1-9. [DOI:10.1186/14726920-6-19] [PMID] [PMCID]

[17] Casacchia M, Bianchini V, Mazza M, Pollice R, Roncone R. Acute stress reactions and associated factors in the help-seekers after the L'Aquila earthquake. Psychopathology. 2013; 46(2):120-30. [DOI:10.1159/000339459] [PMID]

[18] Aliakbari F, Aein F. [Assessing Isfahan emergency nurse competence in disaster response by using national questionnaire (Persian)]. Journal of Clinical Nursing and Midwifery. 2017; 6(3):1-10.

[19] Al Khalaileh MA, Bond E, Alasad JA. Jordanian nurses' perceptions of their preparedness for disaster management. International Emergency Nursing. 2012; 20(1):14-23. [DOI:10.1016/j.ienj.2011.01.001] [PMID]

[20] Mohebi L, Mansoori P, Mohseni A. [Study of nurses' professional competency in emergency ward of Tehran training hospital and pre-hospitals center in disaster and critical events (Persian)]. Paper presented at: Hospital Emergency Conference. 25-27 May 2016. Sari, Iran.

[21] Bahrami M, Aliakbari F, Aein F. [Team work competence in disaster response: A qualitative content analysis study of emergency nurses experiences (Persian)]. Journal of Clinical Nursing and Midwifery. 2014; 2(4):26-36.

[22] Rahmati H, Rambod M, Zare M, Moradian MJ. The effect of crisis management training in traffic accidents with a high rate of mortality using simulated training on knowledge and attitude of nursing personnel. Iranian Journal of Emergency Medicine. 2018; 5(18):1-7.

[23] Inkaew W, Chompunud S. Effects of an interactive teaching method on perceived disaster nursing competencies of undergraduate nursing students. Health Emergency and Disaster Nursing. 2018; 5(1):25-31.

[24] Mottaghian Nezhad A, Dadgari F, Farsi Z. [The effect of education of hospital of incident command system on preparedness of nurses in nuclear accidents in military hospitals of Mashhad (Persian)]. Journal of Military Caring Sciences. 2018; 4(3):147-58

[25] Amerion A, Mahmoudi N, Alidadi A, Sepandi M. The study of effect of performing a plan of training-exercising trauma maneuver on preparedness of the selected military hospitals staff to deal with crisis. Nurse and Physician Within War. 2015; 8(3):5-11.

[26] Shafiei Ae. [The effect of training the principle of surge capacity development to nurses who work at Motahari hospital on preparedness and response capacity of this hospital: using national questionnaire (an action research study) (Perdiam)] Tehran: University of Social Welfare and rehabilitation sciences; 2017.

[27] Karimian A, Khankeh HR, Dalvandi A, Farzin Nia B. The effect of teaching principles of hospital preparedness according to the national program on preparedness of Shahid Motahari burns hospital of Tehran in response to disasters. Health in Emergencies and Disasters Qurterly. 2016; 2(1):25-31.

[28] Delshad V, Borhani F, Khankeh HR D, Sabzalizadeh S, Abaszadeh A. Early warning system and disaster preparedness in Motahari hospital. Journal of Research Development in Nursing \& Midwifery. 2015; 12(2):51-8. 
This Page Intentionally Left Blank 